Japan J. Med. Sci. Biol., 35, 31-35, 1982

Short Communication

\title{
A NOVEL TYPE OF LYMPHOCYTE-MACROPHAGE ASSOCIATION REVEALED ELECTRON MICROSCOPICALLY IN TUBERCULOUS LUNG LESIONS OF MICE
}

\author{
Koomi KANAI, EIko KONDO and Tomoyoshi YASUDA \\ The First Department of Bacteriology, Department of Tuberculosis \\ and Department of Technology, National Institute of Health, \\ Kamiosaki, Shinagawa-ku, Tokyo 141
}

(Received October 8, 1981. Accepted November 27, 1981)

\begin{abstract}
SUMMARY: Electron microscopic survey of tuberculous lung lesions of mice revealed a novel type of lymphocyte-macrophage association. The finger-like projections with sharp or blunt tips of lymphocytes are formed as if pushing deeply the macrophage membrane to form pockets matching the shape of the projections. Intimate membrane contact occurs between these two cells, particularly at the leading edges. The biological significance of this morphological event remains to be a subject for future study.
\end{abstract}

We have been engaged in studies of ultrastructure of mycobacteria (Kanai, Kondo and Yasuda, 1979a, 1981) and cellular response in the alveolar epithelium (Kanai, Kondo and Yasuda, 1979b) using specimens of experimentally produced mouse lung lesions. During the course of these studies, we were also concerned with the morphology of lymphocyte-macrophage interaction in various stages of infection. This communication is to show a novel type of their association by lymphocyte projections.

The specimens were obtained from 50 mice, commercially available ddY strain, which had been infected intravenously with $0.05 \mathrm{mg}$ of a kanamycinresistant strain of $\mathrm{H} 37 \mathrm{Rv}$ tubercle bacilli. The disease produced was found taking the typical pattern of chronic infection, since time-course enumeration of lung viable units (Kanai et al., 1980) showed that the bacilli persisted keeping almost the constant level of viable counts $\left(10^{5}\right.$ to $\left.10^{6}\right)$ up to 12 months. Electron microscopy was conducted with the lung specimens obtained from those mice of various stages of infection. They were killed by iv infusion of $0.1 \mathrm{M}$ cacodylate buffer, $\mathrm{pH} 7.4$, containing paraformaldehyde in $2 \%$ and glutaraldehyde in $2.5 \%$

\begin{tabular}{lcl}
\hline 金井興美（国立予防衛生研究所 & 細菌第一部) \\
近藤犖子（ & 同 & 結核部） \\
保田友義（ & 同 & 技術部）
\end{tabular}


(Karnovsky, 1965). The lungs were removed and ultrathin sections for electron microscopy were prepared therefrom as described previously (Kanai, Kondo and Yasuda, 1979b). They were observed with a Hitachi H-500 electron microscope at $75 \mathrm{kv}$. Light photomicrographs of the Epon-embedded lung lesions were also taken with the sections of one micron thickness stained with $2 \%$ toluidine blue. In this communication, the observations in the mice of 12 month infection are presented.

Light microscopic observation revealed that many granulomatous lesions are scattered in the lung tissue. The main features are the interstitial and intraalveolar cell infiltration and inflammatory exudation by which the normal form of the alveolus is disordered. Unlike the acute phase of infection (Kanai, Kondo and Yasuda, 1979b), polymorphonuclear leukocytes are very few, instead lymphocytes together with macrophages are predominant.

Electron microscopy revealed that most lymphocytes are small lymphocytes having clear mitochondria in one pole of the cell and numerous ribosomes. The round nucleus is very dense with chromatin condensed along the nuclear membrane. This membrane has sometimes a deep unilateral cleft. The cells are not always round, but they take different shapes probably depending upon their activity and the interrelation to adjacent cells and environments. Most macrophages show complicated forms in the lesions extending their cytoplasm into the intercellular space. In addition, we often encountered with very large alveolar macrophages containing numerous inclusion bodies of various shapes and sizes. Some of those inclusions are cristals.

During the survey of many electron micrographs, we noticed not infrequently a particular feature of physical association between macrophages and lymphocytes. These two cell types are often in close contact at the cell membrane, sometimes simply in slight parallel contact over a large area, but on other occasions in tight conjunction by the projections extended from the lymphocytes. The sharp (Fig. 1) or blunt (Fig. 2) tip of the projections is in close contact with the plasma membrane of the partner macrophage. Two or more of this event can be seen in the limited area of the cell surface.

In a more developed and elongated form, such projections are finger-like and round in cross-section (Figs. 3, 4 and 5). They come deeply into adjacent macrophages. Locally, the macrophage membrane is invaginated to form a pocket matching the shape of the projection. It appears that free ribosomes are excluded from the cytoplasm of the projection thus reducing its electron density. The leading edges of projection are in close contact with the partner macrophage. As for macrophages, no specialized structures are seen at the contacting area or its neighbourhood, nor any morphological evidences showing cell degeneration or damage are observed.

The lymphocyte projections observed are quite similar in shape and size to those of cytotoxic T-cells and K-cells demonstrated in vitro by Sanderson and Glauert (1979) and Glauert and Sanderson (1979). These authors devised a method to increase the chances of observing cytotoxic events, otherwise the 
projections were only rarely seen in electron micrographs probably because of their very short time span. In this regard, such high frequency at which we encountered with such projections in vivo is rather striking. An explanation was given by Sanderson (personal communication) that our observation was obtained because of the use of perfusion-infusion which might have fixed successfully the lymphocytes before their projections could retract.

There are some reasons for supposing that the projections are an active process on the part of lymphocytes and do not result from pulling or phagocytizing by the partner macrophage. The macrophage does not show the development of pseudopods to surround the lymphocyte projection from both sides. Unlike the case of interdigitation, free ribosomes and other organelles are excluded from the cytoplasm of projection. The leading tip of the projection is in contact with the macrophage membrane suggesting its development from the point contact formed when the cells first meet each other.

The projections of $\mathrm{T}$-cells and K-cells are interpreted as being responsible for their killing effect on the target cells (Sanderson and Glauert, 1979). In our case, however, there is little evidence to suggest that the lymphocyte projections are working to destroy the partner macrophages. Though our observation is still limited, it would be possible that such lymphocyte-macrophage interaction occurs in the mechanism of cellular immunity. The point contact between these two types of cells is often interpreted as the result of antigen-recognition by the lymphocyte (Glauert and Sanderson, 1979; Podelski and Podelski, 1973). In any case the biological significance of our present finding must be clarified by future study, especially by some model in vitro experiments.

\section{REFERENCES}

Glauert, A. M. And SAnderson, G. J. (1979): The mechanism of K-cell (antibody-dependent) mediated cytotoxicity. III. The ultrastructure of $\mathrm{K}$ cell projections and their possible role in target cell killing. J. Cell Sci., 35, 355-366.

KANAI, K., Kondo, E. AND YASUdA, T. (1979a): Ultrastructural study on mycobacteria in experimentally produced lung lesions of mice. Japan. J. Med. Sci. Biol., 32, 327-336.

KanaI, K., Kondo, E. AND Yasuda, T. (1979b): Ultrastructural changes in the alveolar epithelium in response to mycobacterial infection. Japan. J. Med. Sci. Biol., 32, 315-325.

KanaI, K., Kondo, E., JacQues, P. J. ANd ChIhara, G. (1980): Immunopotentiating effect of fungal glucans as revealed by frequency limitation of postchemotherapy relapse in experimental mouse tuberculosis. Japan. J. Med. Sci. Biol., 33, 283-293.

KanaI, K., Kondo, E. AND Yasuda, T. (1981): An electron microscopy study of intra-cellular mycobacteria in experimental mouse tuberculosis. Tubercle, 62, 187-195.

KARNovsky, M. J. (1965): A formaldehyde-glutaraldehyde fixation of high osmolarity for use in electron microscopy. J. Cell Sci., 27, 137a.

Podelski, W. K. ANd Podelski, U. G. (1973): Circulating cytotoxic lymphocytes in human tuberculosis. Amer. Rev. Resp. Dis., 108, 791-798.

Sanderson, C. J. And Glauert, A. M. (1979): The mechanism of T-cell cytotoxicity. VI. T-cell projections and their role in target cell killing. Immunology, 36, 119-129. 
Fig. 1. Two pointed projections (arrows) from a typical lymphocyte (L) are in contact with a macrophage $(\mathbf{M})$. The sharp tips are in touch with the macrophage membrane making a local concavity.

Fig. 2. A lymphocyte (L) is in close contact with a macrophage (M) in several sites by projections with blunt ends.

Fig. 3. Three finger-shaped projections (arrow) are seen coming out from a lymphocyte (L), two of which appear as if pushing the macrophage membrane to form pockets matching the shape of each projection. The tips of projections are in close contact with the macrophage membrane. The middle projection of the three appears almost fusing into the macrophage cytoplasm at the base. Another lymphocyte (upper left) is also in contact with the same macrophage with blunt protuberances (arrow with a larger head). In such an area, we often see a possible staining artifact of higher electron density.

Figs. 4 and 5. A typical lymphocyte (L) with a small amount of cytoplasm and a few mitochondria having a long projection (arrow) in deep contact with an adjacent macrophage (M). Another projection (double arrow) is seen in cross section within the partner macrophage. 


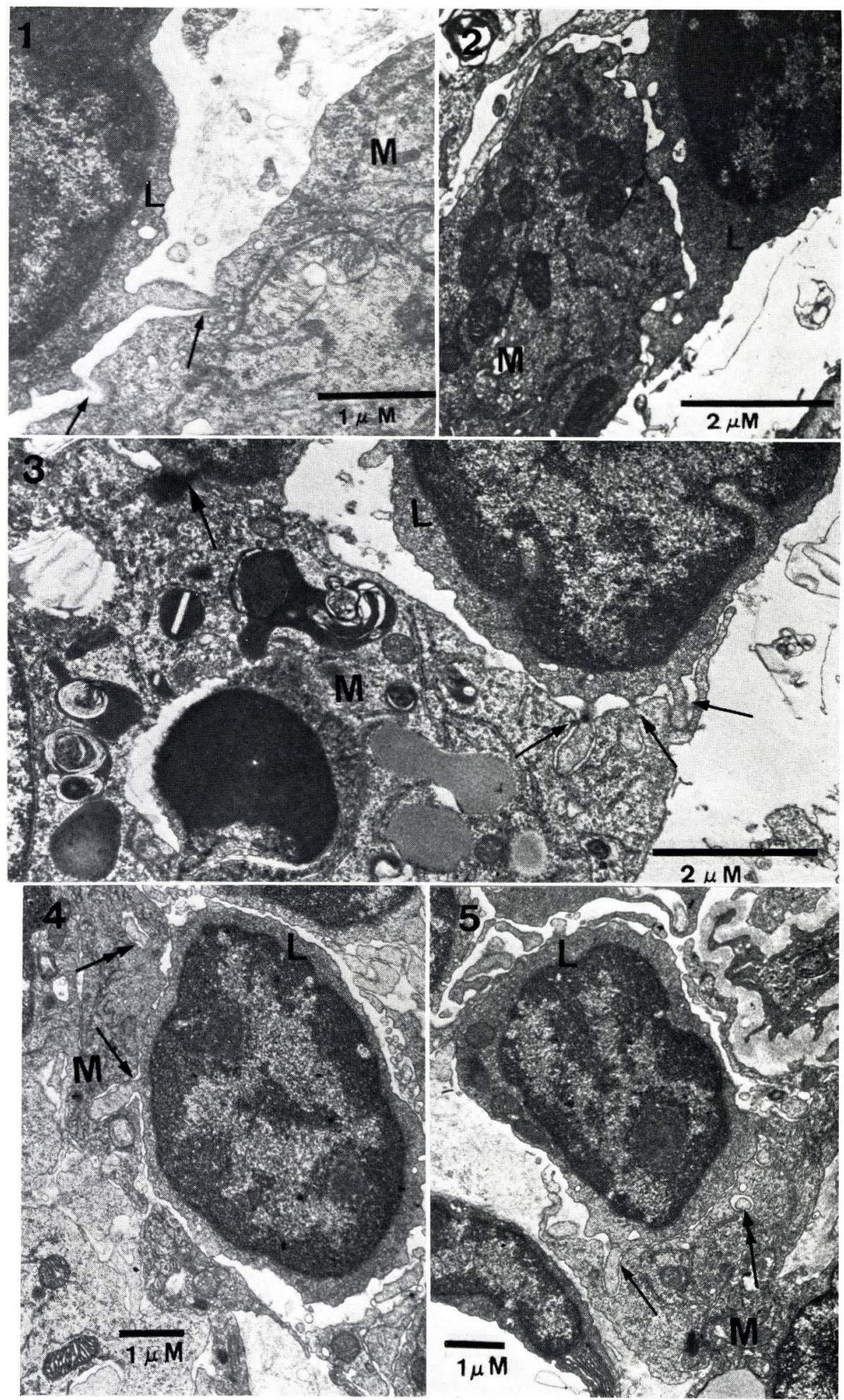

